\title{
Thoughts on Pre-school Education Specialty Construction in Yunnan Higher Vocational Colleges from the Perspective of Industrial and Educational Integration
}

\author{
Zhang Ling \\ Education College of Yunnan Open University \\ Kunming Yunnan 650500 \\ E-mail: 329785240@qq.com
}

\begin{abstract}
In recent years, Yunnan pre-primary services itself is still in the stage of rapid development. It is an important problem worthy of study, how to adapt to the regional industry demand of the rapid development in Yunnan higher vocational pre-school education specialty construction. Facing the opportunities and challenges, Pre-school education specialty in higher vocational colleges in Yunnan province should on the one hand, to appropriately control the scale of enrollment, gradually to meet the market demand within own capacity; on the other hand, to strengthen education integration and the coordinated development of the kindergarten and college, enhance the level of specialty construction, to ensure the quality of talent training, targeted to solve the outstanding problems on four aspects of faculty, curriculum setting, teaching methods and training practice.
\end{abstract}

Keywords-industry and education integration, pre-school education, specialty construction

\section{INTRODUCTION}

In April 2017, Opinions on the Implementation of the Third Phase of the Pre-school Education Action Plan jointly issued by the ministry of education and so on four departments, put forward three years to 2020 the national pre-school kindergarten gross enrollment rat reached 85\%; general kindergarten coverage reached $80 \%$, basically completed the goal of pre-school education public service system construction with wide coverage, profound basic, good quality. It has been cleared about the focus on tasks of increasing general resources supply, deepening the reform of the system and mechanism, improving the quality of conservation and education. Compared with this requirement, Yunnan pre-school education public service system has a large gap and a difficult task.

Pre-school services unit corresponding with university preprimary education major is not just for the kindergarten enrolling 3-6 years old children. There are other pre-school services, such as related to early education, parents (training), toy making institutions, confinement services, etc. "Service content is also more diversified, such as infants and young children conservation and tutor (nursery teacher, professional

Planning project of Yunnan province philosophy, social science and education science, Study on the Interaction Relationship between Specialty Construction and Regional Industrial Development in Yunnan Higher Vocational Colleges, Application No.J2016010093, Project No. AD16010 lactation trainer, parent-children trainer, etc.), children dance choreographer, games toys design, children's psychological counseling and children's show host, pre-school education courseware design, etc." [1] The relevant data and analysis in this paper are mainly aimed at kindergartens with the most representative number and the largest proportion. Talents of Pre-school education specialty construction in higher vocational colleges are also aimed at kindergartens.

\section{Development Status of Yunnan Pre-SchoOl Education Public Service System}

\section{A. The number of pre-school education talents in Yunnan province has increased sharply}

According to statistics, in 2016, there were 1.31 million pre-school education children in Yunnan province, 7310 kindergartens and 41,984 classes in Yunnan province, and the gross enrollment rate did not reach the national average level of 77.4\%. Yunnan's pre-school education is lagging the national average in terms of data, but it will also reach the goal of "Double Popularization" by 2020. With the two-child policy lifted, the number of children of kindergarten age will gradually increase in the next few years.

According to Yunnan Province Makes Efforts on Preschool Education released by Yunnan Province Education Department in April 2018, it demonstrates that in Yunnan province, "in 2017, 4731 private kindergartens, up 13.49\% from 2014, 1610 general kindergartens, increased by $41 \%$ over 2014, 318700 children in kindergarten." This shows a surprising increase. The number and scale of kindergartens in Yunnan province will continue to grow rapidly from 2018 to 2020 to reach the goal of "Double Popularization"in 2020.

In terms of the current number of children enrolling kindergarten, according to the calculation of 30 children in a class in China equipped with "2 education teachers and 1 childcare teacher", the total gap of teachers and childcare workers in Yunnan province is about 35,000.

The reality is that the education and childcare teachers are understaffed. Most of the kindergartens initiatively offer 
internship for trainees, one aim is to supplement understaffed problem, very early booking graduates in higher vocational colleges, hoping to sign the employment intention as soon as possible. In addition, after the national educational requirements for pre-school teachers have been raised, teachers who used to work in kindergartens but did not have relevant educational qualifications can only leave kindergartens; After the release of the second child policy, some teachers in kindergartens choose to get pregnant and ask for maternity leave in these two years. The proportion of female teachers in kindergartens is very large. This is a periodic reason, too. Combined with the kindergarten teachers' heavy work responsibility and workloads, generally lower working conditions, and teachers' professional cannot get the respect and identity they deserve, therefore, it is a big problem that the fast flow and heavy loss of kindergarten teachers. So, except for some important kindergartens with long history, adequate teachers, and higher teachers' quality, most kindergartens have the situation of the lack of faculty and low teacher's quality.

\section{B. The demand for high quality of pre-school education talents in Yunnan province has been greatly increased}

"In new era, variety and diversity of education requires teachers from quantity abundant to quality improvement, teacher law based on education popularization and universalization has not adapted to the demands of a new age, is revised to upgrade." Ni Minjing, a member of the national committee of the Chinese People's Political Consultative Conference (CPPCC) and deputy director of the Shanghai Municipal Education Commission, said pre-school education teachers should be promoted to junior college degrees. In fact, when some kindergartens recruit teachers, it is already a requirement for undergraduate students, even for graduate students.

"In 2017, the number of kindergarten teachers and staff reached 97,600, an increase of 23.67 percent over 2014, and the number of kindergarten heads and full-time teachers who are junior college or above degrees reached 86.3 percent, an increase of 4.5 percent over 2014." The information of Yunnan Province Makes Efforts on Pre-school Education released by Yunnan Education Department in April 2018 also indicates the improvement of academic requirements.

After the national requirements for pre-school teachers' academic qualifications have been raised, some kindergartens have asked teachers who work in kindergartens but don't have relevant qualifications to leave the kindergartens. Due to the low pay, heavy work tasks and other reasons, the kindergarten has a large turnover of personnel, which makes it difficult to retain talents and causes the problem of insufficient quality of talents.

The Yunnan Provincial Government has invested a lot of manpower and material resources to improve the level of kindergarten management, with remarkable results. But the talent demand of pre-school education is very high, no matter from the perspective of national human capital development, or from the inevitable requirement of social and cultural development, or from the parents' more and higher expectations of their child cultivation, requirements to the personnel engaged in pre-school education will only become more and more high.

The only one national committee of the CPPCC in Preschool education field, professor of Beijing Normal University Liu Yan pointed out: "A professional early childhood teacher gets along and exchanges with children like children's psychological researchers, also need to think education methods and strategies like an educator." [2] It is obvious that in recent years, it is difficult for the greatly increased numbers of pre-school teachers to meet the requirements in terms of quality. Kindergartens should improve the level of kindergartens, not only to improve hardware equipment, but also to improve the quality of teachers. Many private kindergartens make visible investment in hardware to attract parents' attention, but their software cannot meet the needs. Other pre-school services have also revealed the same problem.

Along with the advancement of national policy and enhancement of parents' consciousness of children cultivation, the growing demands for general kindergartens, at the same time demands for high quality distinctive kindergartens are also more and more.

\section{Current Situation of Pre-School Education Specialty Construction in YunNan Higher Vocational COLLEGE}

\section{A. The number of pre-school education majors in Yunnan} higher vocational colleges has increased significantly

To be in accordance with national requirements in 2020, to realize the goal of "Double Popularization", vigorously supports have been enforced to the expansion of recruitment scale of pre-school education major students in colleges and universities in Yunnan province. In recent years, recruit number of junior college and undergraduate pre-school education major students is up to more than 5000 people a year.

Colleges with pre-school education major expanded rapidly, doubling their enrollment. Some colleges used to only have junior college pre-school education major, now added the undergraduate pre-school education major. Some of the preschool education major schools that have been established in secondary vocational schools are directly transformed and upgraded to pre-school education vocational colleges of normal schools. In addition, some schools have opened remote preschool education or art schools, on this basis; they have quickly declared pre-school education major. In 2017, Yunnan province has 11 colleges opened junior college and undergraduate pre-school education specialty.

These higher vocational colleges do not worry about the shortage of students, often the actual enrollment can exceed the planned number. Because the stock of pre-school education professional technical secondary school students in Yunnan province is very big, under the new situation demands, secondary vocational education cannot meet the needs of the market, also do not conform to the state academic requirements to pre-school education teacher, and secondary vocational students age small, their family don't need these students employed immediately, these students need urgently upgrading from secondary vocational to junior students. At the same time, 
ordinary college entrance examination enrollment is also very popular, especially among girls due to the professional characteristics.

\section{B. Major quality problems exist in the construction of pre- school education major in higher vocational colleges}

\section{1) Weak faculty}

In 2014, pre-school education in higher vocational colleges professional development has been slow, university pre-school education specialty construction scale is limited, recruitment of postgraduate and doctoral graduates is less, few teachers engaged in pre-school education major education in colleges and universities. Suddenly, there are so many vocational schools specializing in pre-school education in China, and the teaching force of all colleges and universities is seriously insufficient. It is said that less than $10 \%$ of teachers with preschool education degrees. Almost all the colleges we found faced this problem. Many colleges employ many external teachers, some of them are mainly graduate students who lack of teaching experience, and some are mainly teachers with related majors who lack of pre-school education professional knowledge and ability. There are more theoretical teachers and fewer "Double Teachers Type" (both theory and practice) teachers. Teachers usually have a large workload, and schools are not willing to create opportunities for further learning. Teachers' professional growth is slow and cannot meet the requirements of talent training.

2) The course setting and course content are not in line with the occupational standards and kindergarten work

The curriculum setting of pre-school education major can be roughly divided into five types: public basic course, professional basic course, professional skill course, professional core course and professional development course. These courses are closely related to the goals of pre-school talent training and should be an orderly and changeable system. In many colleges curriculum types are indistinguishable from each other; courses that are less relevant to their major are set as compulsory courses, such as music history. And work closely related to regional industry development content cannot be converted into curriculum, for example, a general curriculum 'teaching method" summed up language, health, science, society, art five fields of education activities in the kindergarten and the limited class time is set up. Also, curriculum development cannot be carried out according to changes in market demand, such as Montessori education, Orff music education, etc.

Some higher vocational colleges directly ignore the public basic courses and ignore students' necessary general knowledge education. However, professional basic theory courses with characteristic of subject courses, which are highly theoretical and systematic, account for a large proportion. The learning effect of students is not good enough and cannot be translated into professional ability. There are many art teachers in some colleges and universities, which highlight the professional skills courses. Students with these skills cannot use these skills flexibly and appropriately in pre-school education. Generally, it shows that comprehensive core courses are not arranged in enough time, some are even quite insufficient, and there is no corresponding opportunity for curriculum practice. Some colleges and universities set a lot of repetitive content, did not carry out integration, and wasted students' time.

The curriculum is not systematic, and it is also reflected in the arrangement of curriculum order. For example, in some colleges and universities students have started pre-school health education before pre-school children's sanitary and health care study, which is not consistent with the law of students' progressive learning.

All these reflect the disconnect between curriculum design, curriculum content and professional standards, and the actual work of kindergartens. Students spend time and energy to study, but it is common that students fail to learn systematically, effectively and practically.

3) Outdated teaching concepts and teaching methods make it difficult to guarantee the requirements of personnel training for professional ability and key ability

Most teachers are accustomed to traditional teaching methods, mainly lecturing, and cannot adapt to the changing requirements of industrial development. Old teachers do not want to improve, new teachers have not yet found out effective teaching methods. Higher vocational students are generally not the best source of students, many teachers have lower expectations for them, and naturally lower requirements. Teachers must finish their teaching curriculum; they are too busy to take care of their own professional growth to consider the improvement of teaching quality. In addition, due to students need to learn more content in limited time, their teachers pay attention to the progress and neglect the quality. The characteristics of the students in different times have also changed. Teachers feel that higher vocational students are difficult to teach, but they fail to consider changing teaching concepts and improving teaching methods to achieve different effects. Different teaching contents combined with different talents training objectives also require teachers to constantly experiment with better teaching methods. Although there are multimedia and hypermedia now, it seems everybody is in use generally; teaching by these means is only convenient for teachers' 'teaching", it does not play a better role on aspect of the students' "learning". The students' pre-school education professional ability developed inadequately, but also caught the consistent attention of students and teachers, however, be negligent in students' cooperation ability, creation ability and so on key ability, lack of the teacher's teaching idea, and it has not embodied in the teaching methods.

4) Insufficient Training and Internship Conditions and Insufficient Guidance

Some newly opened colleges of pre-school education major have lagged in the construction of practical training rooms, which cannot meet the requirements of students' practical training. The change of pre-school market and the addition of new courses require new training rooms. For example, Montessori training room, if not, it is almost impossible to carry out Montessori teaching. The internship schedule in kindergartens is insufficient, and many colleges put the internship in the third year, while the internship schedule in the first grade and the second year is only one day and two days, which is not related to the course content. Due to the shortage of "Double Teachers Type" (both theory and practice) teachers, 
there is a lack of guidance for practical training practice, which mainly depends on the internship at the internship base. However, many kindergartens use interns as childcare workers, and they are reluctant in teaching guidance, which cannot meet the needs of students' development.

\section{INTEGRATION OF INDUSTRY AND EDUCATION, UPGRADING OF SPECIALTY CONSTRUCTION, AND ENSURING THE QUALITY Of PERSONNEL TRAining}

The rapid development of pre-school education service agencies, kindergarten as the main body, led to the development of pre-school education major in higher vocational colleges, pre-school talents with pre-school education professional training in higher vocational colleges need to be able to meet the needs of the market, it is not only the amount, but also the quality. Blind expansion of recruitment brought about the reaction of dyspepsia. The sustainable development of a major in a college must be centered on the cultivation of high-quality talents.

The National Education Career Development the Twelfth Five-year Plan clearly put forward that to encourage local and industry from its own reality, to achieve a variety of forms of combination and cooperation between industry and teaching , colleges and kindergartens, to promote the vocational colleges' curriculum settings work with industry layout, course content with professional standards, teaching process with industry process, education certificate with qualification certificate, vocational education with industry and lifelong education. In “The Special Program of Higher Education”, it is also clearly proposed to expand the development space of higher education institutions, enhance their ability to serve the industry, and establish the interaction mechanism between education and industry.

Pre-school education major in higher vocational colleges in Yunnan province, therefore, should properly control of enrolment, at the same time, strengthen the integration between industry and education, through the kindergarten and college coordinated development to speed up the quality improvement, in view of the quality problem to do a good job on four aspects, to ensure quality of talent training, to ensure the service quality of pre-school education in Yunnan province.

A. To strengthen cooperation between industry and education and accelerate the construction of "Double Teachers Type " (both theory and practice) faculty through multiple channels

"Hundred years layout, education is the basis. Education business, teachers are the foundation." Teachers are the most important software, and all teaching ideals ultimately need to be implemented by teachers, and all teaching behaviors are ultimately guaranteed by teachers. The pre-school education major in higher vocational colleges needs a team of "Double Teachers Type "(both theory and practice) teachers with excellent professional skills. In view of the current shortage of teachers, higher vocational colleges should vigorously promote the cooperation between industry and education, and directly employ kindergarten teachers to undertake the task of teaching and practical guidance, to supplement the strength of teachers.
At the same time, send teachers to further study in kindergartens, promote the development of college teachers to "Double Teachers Type" (both theory and practice) teachers, and enhance the ability of teachers' practical guidance in higher vocational colleges. Vocational colleges and kindergartens can cooperate with each other through some cooperative projects to complement each other's strengths and promote the professional development of teachers.

\section{B. To strengthen the connection between curriculum setting and vocational standards, and to strengthen the curriculum of kindergarten work process analysis}

In 2004 professor Zhao Zhiqun pointed out that "on a world scale, the development of vocational education curriculum went through 'subject systematic', 'learning theory-oriented' and 'professional analysis-oriented' mode, is to develop to 'working process-oriented' development mode." [3] As a matter of fact, until now, the development of pre-school education working process-oriented comprehensive curriculum is not enough. Working process-oriented course requirements to choose fields which need to learn and can learn, in the form of a project to transform it into the course content, and students achieve professional ability and comprehensive ability ascension through completing the project. The corresponding teaching method of this course pays more attention to practice. It is to do in learning and lean in doing, which can well stimulate students' learning enthusiasm and cultivate their autonomy and creativity.

Pre-school teacher, childcare worker, the kindergarten head jobs are practical specific things, to analyze of the typical working process, and transform it into practical curriculum content, "granularity" in the project form, in students' learning process, teachers and students together to give theoretical description and explanation, in specific operations, truly theory and practice in one.

Each pre-school education specialty of higher vocational colleges combines professional advantages and conditions of their institutes, considering the development of pre-school education specialty characteristics of the colleges and universities, to make long-term planning, according to the needs of the vocational work position, to develop professional courses, to create a professional characteristic, more fit to the needs of the development of regional industry.

\section{To improve the teaching concept and strength the improvement of the capacity-oriented teaching methods}

The training target of pre-school education talents needs to keep pace with The Times, and it cannot be satisfied with the skills of pre-school education major, and it must have education ability. Can't to get satisfied with professional ability, also need to play key professional ability in the practical work, including the independent learning ability, communication ability, cooperation ability, reflection ability, innovation ability, etc.. In this way, the students can adapt to the development and change of regional industry and keep pace with The Times.

Single traditional teaching method apparently can't meet the ability training requirements, teachers need to update the education idea, adjust the personnel training target, practice 
diversified teaching methods, let the student to do in learning and to learn in doing, and to gain maximum ability ascend on more aspects in limited teaching time.

\section{To strengthen the deep integration of industry and education and to improve the practical training and practice system}

On the one hand, higher vocational colleges need to speed up the construction of teaching hardware facilities, such as training room, to meet the teaching needs of practical courses. On the other hand, by strengthening the deep integration of industry and education, and taking kindergartens as the training base, to innovate the construction and operation mode of the practice base and play the role of the training base. "Widely set up practice base, and form continuity and long-term cooperative partnership with kindergartens, and make student trainee mode normalized, with time and place flexibility, and trainee form diversification, and work closely with the kindergarten to organize students' practice activities. Kindergartens become extending classroom of theory knowledge, colleges become a place for practice and promotion, with improvement of the effect of students' learning interest and effect, which inevitably can lead teachers to raise their professional level, it is a "teaching" and "learning" benign development." [4] From the orientation of the work process of classroom teaching content to the practical training in the training room, to the skills competition, to the internship and the class following internship and the on-the-job internship, the practical training internship system of the whole process has been formed.

In a word, to get a breakthrough in talent training in higher vocational pre-school education, it can't get rid of the cooperative relationship with pre-school service organizations represented by kindergartens. The talent training mode of school-enterprise cooperation is carried out generally. The effect of the cooperation depends on the depth of cooperation, whether the cooperation is real or multi-directional. Kindergarten is not only the students practice base, the curriculum setting participants, the talent training evaluators, the trainee interns, "Double Teachers Type" (both theory and practice) pre-school teachers training place, pre-school education research origin, and the replenishment of the lack of pre-school education teachers of higher vocational, etc. Therefore, the cooperation between higher vocational preschool education colleges and kindergartens should be deep and effective. Careful analysis of present situation and future trend of pre-school education development in Yunnan province, in contrast, watch pre-school education major construction problems in higher vocational colleges in Yunnan province, pre-school education major in higher vocational colleges need to strengthen the depth of industry and education integration, the coordinated development of kindergarten and college, promote each other, make progress together.

\section{REFERENCES}

[1] Guan Qing. Problems and Countermeasures of Pre-school Education Major Construction at the Junior College Level After the Transformation, Modern Education Management, 2012, 11th Issue :95-98

[2] Liu Yan. How can Pre-school Education Reassure Parents, China Education Daily 20180307

[3] Zhao Zhiqun. On the Comprehensive Curriculum Development of Vocational Education Work Process Oriented, Vocational Education BBS, February 2004:4-7

[4] Ma Xiaochun. An Effective Approach to the Professional Development of Pre-school Education Teachers from the Perspective of "College and Kindergarten Cooperation" in the Context of the Promotion of Young Teachers. Journal of Heilongjiang Education College, vol.35, No. 10 2016: 26-28 